Rakenteiden Mekaniikka (Journal of Structural Mechanics)

Vol. 53, No. 4, 2020, pp. 308-328

https://rakenteidenmekaniikka.journal.fi/index

https://doi.org/10.23998/rm.83573

(C) 2020 The Authors

Open access under license CC BY 4.0

\title{
Fretting test rig with variable normal force
}

Jaakko Meuronen, Antti Mäntylä, Joona Vaara, Jouko Hintikka, Janne Juoksukangas, Arto Lehtovaara and Tero Frondelius ${ }^{1}$

Summary Fretting is small amplitude reciprocating sliding between surfaces, and it may quickly causes surface cracks, which can continue growing under cyclic loads, until the structure breaks entirely as a result of the fretting fatigue. Fretting can also produce hardened wear particles as a result of adhesive wear, which then accelerates abrasive wear. In this case, the community uses the term fretting wear. The design of heavily loaded contacts, susceptible to fretting, is a difficult task because there is no generally accepted design guide. More extensive fretting research is needed to create them. This paper introduces detailed design phases for a equipment (rig) for a variable normal force fretting test. Supporting high radial and normal forces such that there is minimal run-out between the specimens was the most significant design challenge. The combination of a hydrostatic radial bearing and elastic torque shaft was selected for the detail design phase based on FE-analyses, calculations, and overall evaluation. The frame of the test rig consists of the main frame, which supports mainly the normal force and two torque frames, which support torque cylinders. Many solutions, which were found to be working in the current "ring-ring" apparatus of Tampere University, could be utilized in the new test rig like the tapered connections of the specimens, the elastic rod of the torque lever, axial displacement plate, and contact pressure adjustment system. The designed test rig enables fretting tests with $0 \mathrm{~Hz}$ to $20 \mathrm{~Hz}$ cycle frequency so that normal and tangential force or displacement can be controlled independently of each other. The normal force cannot change from compression to tension dynamically, but the adhesive force of the contact can be measured by slowly increasing the tension force. The designed fretting test rig fulfills all essential requirements, which were set.

Key words: product development, testing machine, fretting fatigue, fretting wear, friction

Received: 4 July 2019. Accepted: 24 March 2020. Published online: 20 October 2020.

\section{Introduction}

A relentless pursuit of increasing the performance of combustion engines leads to the higher utilization of fatigue strength of the components, see Frondelius et al. [1], which gives a comprehensive history of all fretting related research for safer marine engines. Many engine parts are clamped together by the normal force, and although they seem to be at rest relative to each other, there may occur reciprocating slipping between mutual contact areas, see Mäntylä et al. [2] for an example. When parts are separated, visible surface damage, called fretting damage, can be found although slip amplitude would have

\footnotetext{
${ }^{1}$ Corresponding author: tero.frondelius@oulu.fi
} 
been only a few micrometers in size. If also, the cyclic stresses are high enough, fretting fatigue can occur. Surface sliding with higher amplitude movement induces fretting wear that generates oxide wear debris between the surfaces. Fretting may be a problem, for example for shrink fits, bolted parts and splines. [3, 4]

The history of fretting machines development in Finland goes in five cycles. The first fretting rig in Helsinki University of Technology, now called Aalto University, was build in MTS hydraulic test frame. The rig had the line contact. The second fretting rig in the Tampere University of Technology, now called Tampere University, was a dedicated fretting fatigue machine with Hertzian point contact, see Pasanen et al. [5] The theoretical basis and the corresponding simulation results for the point contact fretting behavior is given in Lehtovaara and Rabb [6]. This has been a successful test rig with a lot of test results i.e Hintikka et al. $[7,8]$.

The third rig was for complete contact having an edge singularity, see Juoksukangas et al. [9]. The fourth rig is a so-called annular flat-on-flat test device, which has been the most successful rig until now. The analyses of the results are shown in Hintikka et al. [10-13]. The fifth rig is bolt contact, see Juoksukangas et al. [14]. The latest results from Mäntylä et al. [15] shows a good correlation between measured and simulated fretting scars.

The effects of fretting wear, fatigue and corrosion are challenging to take into account in a product development process, and designers are often unsure what coefficient of friction $(\mathrm{COF})$ value to use when dimensioning contacts, see the latest results from Juoksukangas et al. [16]. COF is not constant relating only to a material pair, but numerous parameters may affect it. Several non-idealities have been identified in fretting induced friction, fretting wear and fretting fatigue [12]. For example, so-called non-Coulomb friction has been measured to occur with quenched and tempered steel fretting contact where the friction force increases substantially during each fretting cycle when the fretting motion approaches it extreme position [17]. This has been explained by mechanical interlocking of material transfer spots. Recent studies $[18,19]$ show that fretting induced cracks are present in the adhesion spots, and that those cracks form during the first few thousands of load cycles. The crack length has been measured to be more than one millimeter with low nominal load levels and without external cyclic stress. Such cracks can easily continue to grow if cyclic bulk stress is present. Importantly, this kind of fretting induced adhesion and cracking can explain fretting fatigue failures of large flat-on-flat contacts under low nominal stress conditions.

There is not yet a generally accepted fretting theory, which could act as a basis for a fatigue design procedure, which involves the effects of fretting such as the formation and cracking of adhesion spots. Well designed laboratory experiments are needed to determine COF reliably for different contacts, and extensive testing is needed to develop the design procedure against fretting damage. The study aims to develop a fretting test rig, which can be used for testing extensive annular flat-on-flat contacts with high dynamic normal force, which is controlled independently from the tangential force. The contact pressure should be even, and specimens should stay concentric during tests. Developed fretting test apparatus should enable large-scale experiments with the main measured parameters of frictional torque and sliding amplitude aiming to understand better the evolution of fretting induced friction, wear, and fatigue with different specimen geometries and materials. Also, special attention was given to capability to measure and control the forces and displacement related to the initial adhesive wear phase as precisely as possible. 


\section{Detailed design of the fretting rig}

The concept design is out of the scope of this paper, and the plan is to write another paper focusing on the systematic concept design phase. The detail design phase started after selecting the best concept. Figure 1 lists the fretting test rig main sub-assemblies in the same numerical order as they appear in the following subsections.

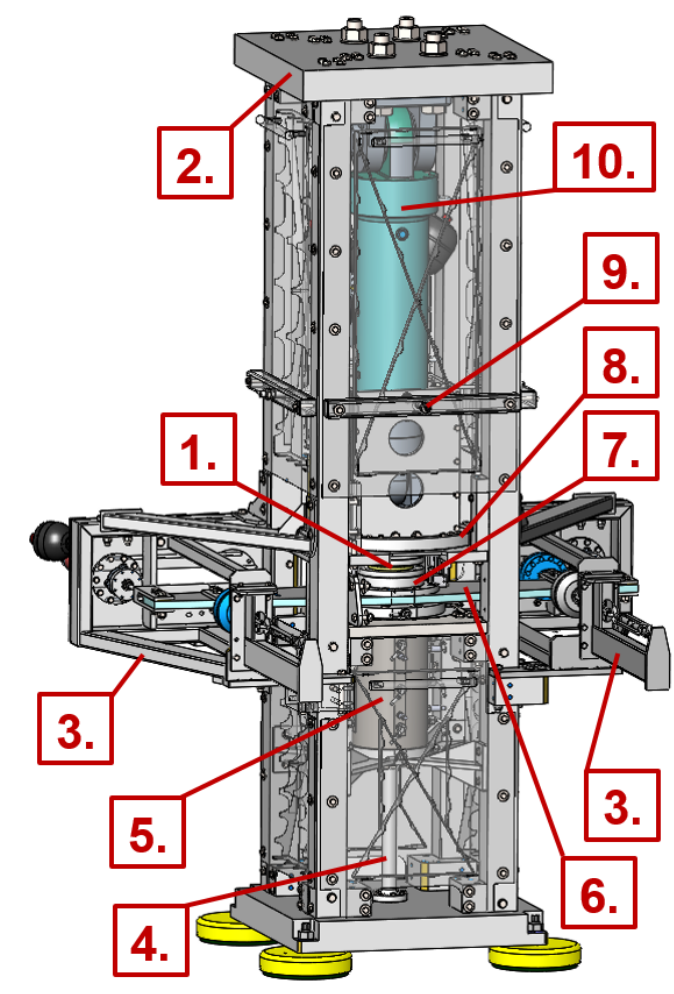

\section{Specimens}

2. Main frame

3. Torque frame

4. Elastic torque shaft

5. Hydrostatic bearing

6. Torque lever

7. Specimen holders

8. Elastic axial displ. plate (EP)

9. Contact pressure adjustment

\section{Hydraulics}

Figure 1. Main subassemblies of fretting test rig

\section{Specimens}

At the final meeting of the concept design phase, it turned out that it would be desirable if specimens with $150 \mathrm{~mm}$ outer diameter (D) could be tested with $10 \mathrm{MPa}$ contact pressure. It was decided that inner diameter (d) of the largest specimen is $100 \mathrm{~mm}$ and thickness (t) of the tubular section is $25 \mathrm{~mm}$. $98.2 \mathrm{kN}$ normal force is needed to create $10 \mathrm{MPa}$ contact pressure with the D150d100t25 specimens. Meuronen [20] calculated that $250 \mathrm{kN}$ is enough normal force for $400 \mathrm{MPa}$ contact pressure tests.

The final dimensions of specimens of $400 \mathrm{MPa}$ tests are D38d26t6. Specimens attached to the holders are in Figure 2. Required normal force is $241.3 \mathrm{kN}$ and torque $6047 \mathrm{Nm}$. Needed cylinder forces are of the same order of magnitude for $10 \mathrm{MPa}$ and $400 \mathrm{MPa}$ tests. Therefore two $500 \mathrm{~mm}$ levers seemed appropriate before realizing how the torque cylinders need different stroke lengths, see Table 1. The D150d100t25 specimen needs to turn much less compared to D38d26t6 specimen, to achieve the same sliding amplitude, because the radiuses and compliances of the specimens are so different. The shims do the axial position tuning of the lower specimen. 


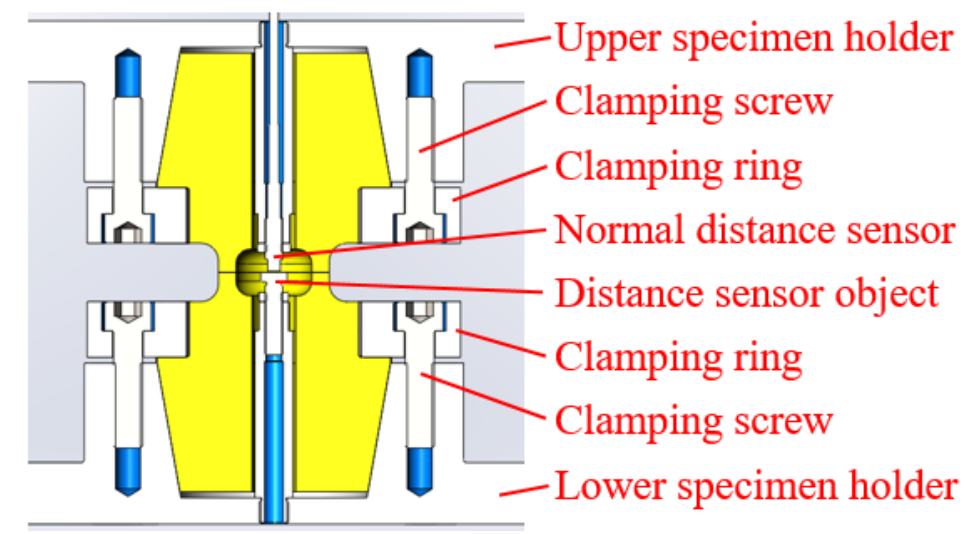

Figure 2. Section view of two D38d26t6 specimens (yellow) and specimen holders.

\section{Tapered connection}

A hydraulic sleeve clamping and a tapered connection with a couple of different tightening methods were the seriously considered options for attaching a specimen to a specimen holder. A compact size of the tapered connection was the most compelling reason why it was preferred. The old test machine used M10 pulling screws to tighten the tapered connection. The screw in the fixed specimen holder is hollow and threaded so that a distance sensor fits inside the screw. It could have been an excellent method, but in the new rig, access to the back screw is going to be denied, because the normal force cylinder is attached straight to the backplate, which is attached on top of the elastic axial displacement plate (EP). The upper specimen holder is screwed under the EP so that screws go through the EP to the backplate, which has threads for them. Removing the cylinder was considered more difficult than tightening a few clamping screws evenly.

To dimension different size conical connections, we made Mathcad calculations according to the instructions of Airila et al. [21]. Another Mathcad worksheet calculates, according to VDI 2230 standard, the effect of COF on the tensile force of the clamping screws. For 8.8 strength M10 screw, $48 \mathrm{Nm}$ tightening torque is needed to achieve $27.5 \mathrm{kN}$ clamping force, when COF is 0.12. It is important to keep COF similar to different clamping screws because a five percent increase in COF means that $3.5 \mathrm{Nm}$ torque increase is needed to achieve the same clamping force. [20]

According to Yoshimi et al., the tapered connection is self-holding, if a taper angle is between $2^{\circ}$ to $3^{\circ}$ and self-releasing, if the taper angle is more than $16^{\circ}$ [22]. The new taper angle is $20^{\circ}$ to secure the specimen detachment. After a couple of iterations with Mathcad, the final dimensions of the D38d26t6 specimen were achieved, and a crosssection of the specimen is in Figure 3. Dimensions of D150d100t25 specimen are also in the same picture. When the larger diameter of the taper is $176 \mathrm{~mm}$, the specimen turning from $180 \mathrm{~mm}$ diameter $34 \mathrm{CrNiMo6}$ steel bar is possible.

\section{Compliance}

FE-analysis was performed with SW Simulation to find out compliance factors of different specimen sizes. First, an assembly was made, where two identical specimens were mated against each other, as shown in Figure 4. Because compliance factor value $1.16 \times 10^{-5} \mathrm{rad} / \mathrm{Nm}$ for the current D25d15t5 specimen, had already been calculated by Hintikka [23], it could be used to verify the FE-simulation method used here. The ta- 

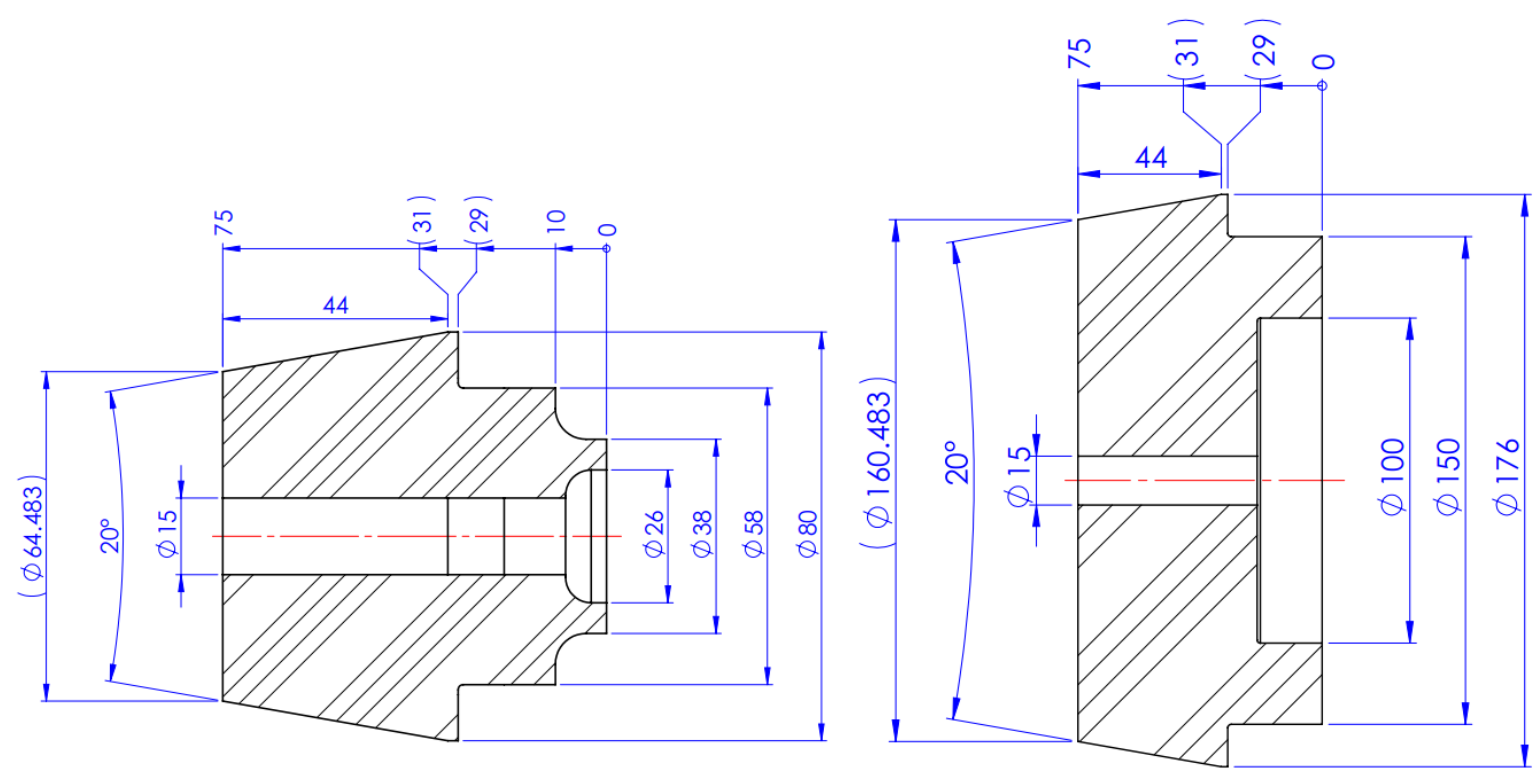

Figure 3. The principal dimensions of D38d26t6 and D150d100t25 specimens

pered part of the lower specimen was fixed in the simulation, and $141.372 \mathrm{Nm}$ torque was targeted to the tapered portion of the upper specimen. Mesh details are in Figure 4. In thin areas, a high mesh density meaning $0.5 \mathrm{~mm}$ element size was used. The result of the simulation is in Figure 4. Rotational displacement $\Delta s$ is $0.029761 \mathrm{~mm}$ when an observation radius $r$ is $20 \mathrm{~mm}$. Already 347849 element mesh resulted in $0.029756 \mathrm{~mm}$ rotational displacement, so mesh quality is sufficient.
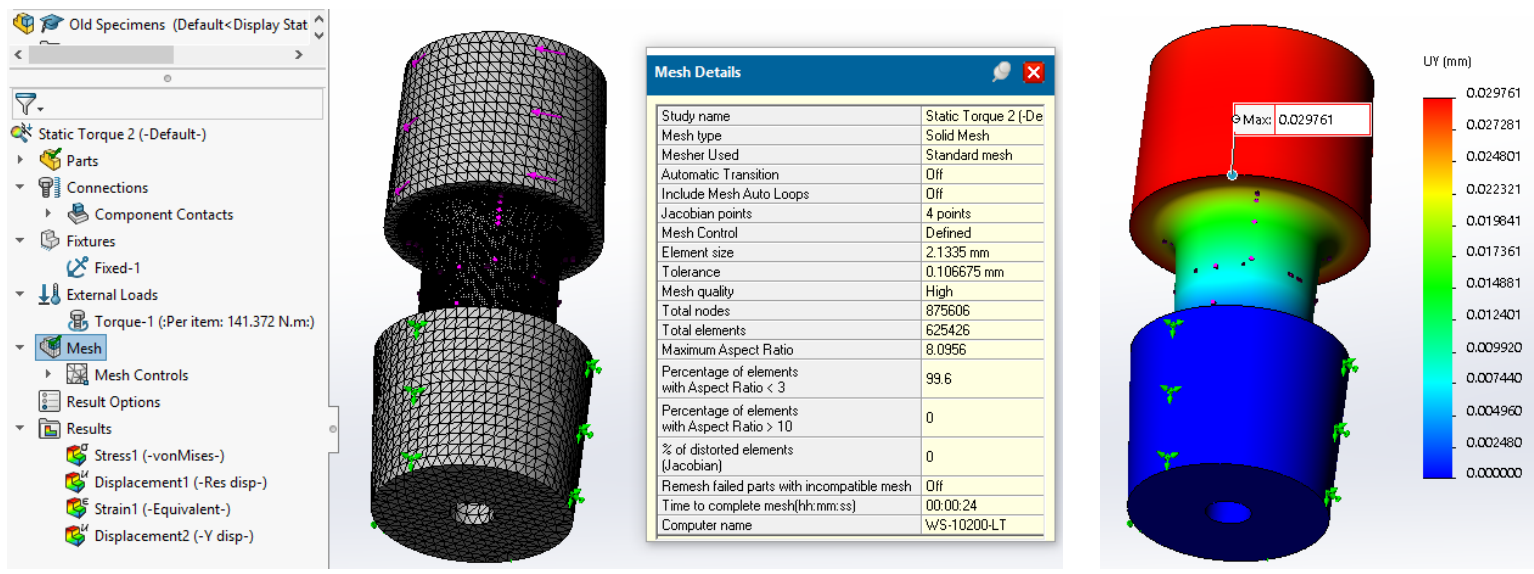

Figure 4. Mesh details of two D25d15t5 specimens and rotational displacement result around central axis of specimens

Because an exact determination procedure of reference value $1.16 \times 10^{-5} \mathrm{rad} / \mathrm{Nm}$, was unknown, the result was considered accurate enough although it is $10.2 \%$ smaller. The same procedure was used to calculate $2.1007 \times 10^{-6} \mathrm{rad} / \mathrm{Nm}$ compliance factor for D38d26t6 specimen and $2.4815 \times 10^{-8} \mathrm{rad} / \mathrm{Nm}$ compliance factor for D150d100t25 specimen.

When the compliance factors were calculated, approximated stroke lengths for torque cylinders could be calculated with Excel. The results are shown in Table 1. When the 
contact pressure and compliance factor are high, the effect of compliance on the required stroke length is significant. If D38d26t6 specimens were utterly rigid, only $2.5 \mathrm{~mm}$ stroke would be needed with a $400 \mathrm{~mm}$ lever. When compliance of test specimens is considered, $10.5 \mathrm{~mm}$ stroke is needed. To balance the stroke differences, and increase available torque, authors decided to use one long lever with mounting holes for cylinders in both $400 \mathrm{~mm}$ and $800 \mathrm{~mm}$ lever lengths.

Table 1. Needed strokes calculated for D38d26t6 and D150d100t25 specimens

\begin{tabular}{|c|c|c|c|c|c|}
\hline Initial data: & & $\begin{array}{r}500 \text { mm LEVER } \\
\text { D38d26t6 }\end{array}$ & $\begin{array}{l}500 \mathrm{~mm} \text { LEVER } \\
\text { D150d100t25 }\end{array}$ & $\begin{array}{r}400 \mathrm{~mm} \text { LEVER } \\
\text { D38d26t6 }\end{array}$ & $\begin{array}{r}800 \text { mm LEVER } \\
\text { D150d100t25 }\end{array}$ \\
\hline Tube thickness [mm] & $t_{t}$ & 6.0 & 25.0 & 6.0 & 25.0 \\
\hline Inner radius [mm] & $r_{i}$ & 13.0 & 50.0 & 13.0 & 50.0 \\
\hline Outer radius $[\mathrm{mm}]$ & $r_{o}$ & 19.0 & 75.0 & 19.0 & 75.0 \\
\hline Middle radius [mm] & $r_{m}$ & 16.0 & 62.5 & 16.0 & 62.5 \\
\hline Normal pressure [MPa] & $p_{N}$ & 400.0 & 10.0 & 400.0 & 10.0 \\
\hline Sliding amplitude [mm] & $u_{a}$ & 0.05 & 0.05 & 0.05 & 0.05 \\
\hline $\operatorname{MAX} \operatorname{COF}[-]$ & $\mu_{M}$ & 1.5 & 1.5 & 1.5 & 1.5 \\
\hline Lever length [mm] & $L_{L}$ & 500.0 & 500.0 & 400.0 & 800.0 \\
\hline Number of levers [kpl] & $n_{L}$ & 2.0 & 2.0 & 2.0 & \\
\hline Compliance factor [rad/Nm] & $k$ & 2.1007E-06 & $2.4815 \mathrm{E}-08$ & $2.1007 \mathrm{E}-06$ & $2.4815 \mathrm{E}-08$ \\
\hline Torque correction factor [-] & $c_{t_{-} k}$ & 0.822 & 0.822 & 0.822 & 0.822 \\
\hline Calculations: & & D38d26t6 & D150d100t25 & D38d26t6 & D150d100t25 \\
\hline Relative radius difference [\%] & $r_{\%}$ & 37.50 & 40.00 & 37.50 & 40.00 \\
\hline Nominal contact area $\left[\mathrm{mm}^{2}\right]$ & $A_{n}$ & 603.19 & 9817.48 & 603.19 & 9817.48 \\
\hline Rotation amplitude [rad] & $\alpha_{a}$ & 0.0031 & 0.00080 & 0.0031 & 0.00080 \\
\hline Normal force $[\mathrm{N}]$ & $\boldsymbol{F}_{n}$ & 241274.32 & 98174.77 & 241274.32 & 98174.77 \\
\hline Tangential force $[\mathrm{N}]$ & $\boldsymbol{F}_{t}$ & 361911.47 & 147262.16 & 361911.47 & 147262.16 \\
\hline Friction torque $[\mathrm{Nm}]$ & $T_{f r}$ & 5790.58 & 9203.88 & 5790.58 & 9203.88 \\
\hline Needed force $[\mathrm{N}]$ & $\boldsymbol{F}_{t c}$ & 5790.58 & 9203.88 & 7238.23 & 5752.43 \\
\hline Compliance angle [rad] & $\theta_{k}$ & 0.010 & 0.00019 & 0.010 & 0.00019 \\
\hline Needed stroke (ca.) [mm] & $S_{c}$ & 13.12 & 0.99 & 10.50 & 1.58 \\
\hline
\end{tabular}

\section{Main frame}

The mainframe of the fretting test rig needs to be very rigid, and it should provide attachment points for other parts. First, authors considered a cheap welded frame from RHS-pipes, but quickly it was realized that for adequate accuracy, mounting surfaces and holes need to be machined after the welding, which would be difficult, so bolted joints were preferred instead. Four long steel bars were fixed between top- and bottom plates, according to Figure 5. The elastic axial displacement plate (EP) with a diameter of $600 \mathrm{~mm}$, is dimensioned in [20]. It should fit between the vertical bars of the frame, so the minimum distance between the vertical bars was known. The needed height for the frame is estimated from the height of the layout assembly. The frame will have an attachment plate in the middle. A sketch model and preliminary FE-analysis of the frame was made 
with Solidworks. When $250 \mathrm{kN}$ force was directed to $200 \mathrm{~mm}$ diameter circle areas in top and bottom plates, reasonably small $0.2 \mathrm{~mm}$ maximum displacement and under $30 \mathrm{MPa}$ von Mises stress were achieved.

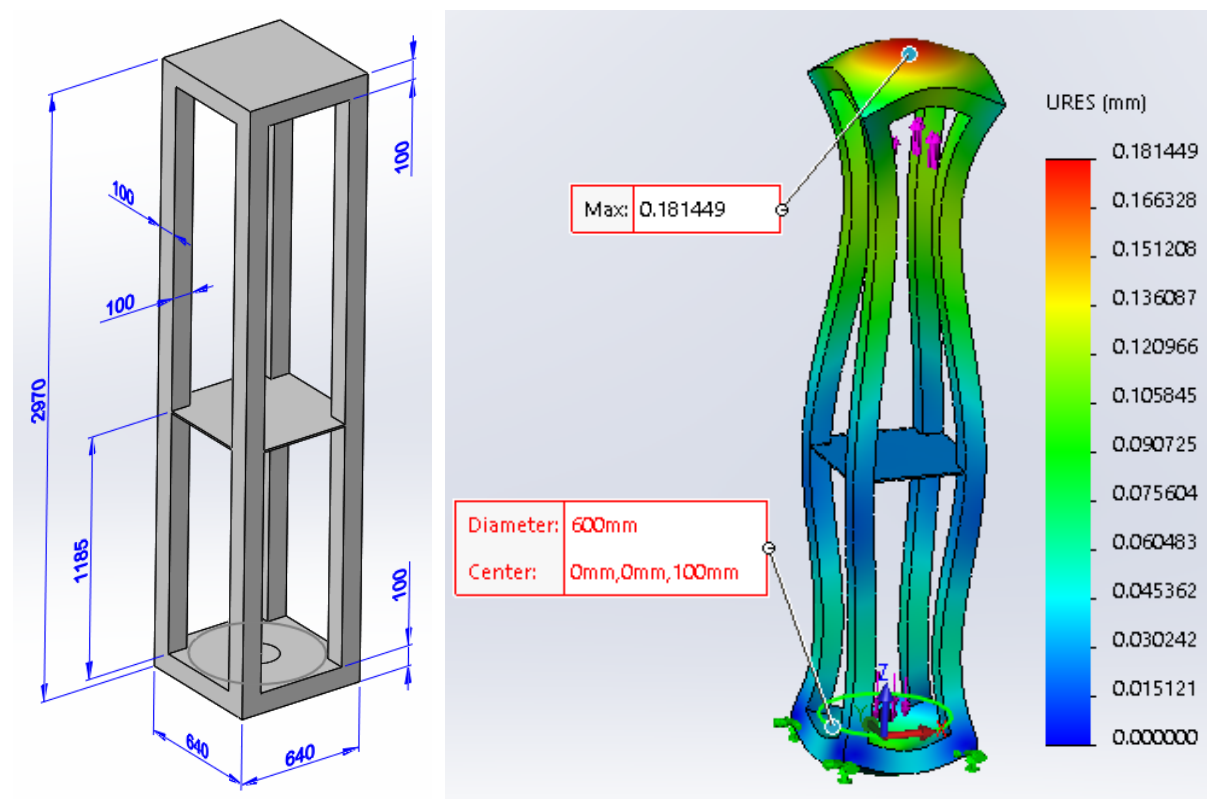

Figure 5. Dimensions and FE-analysis for frame sketch made with Solidworks.

Vertical bars were designed to be identical, which make them modular as well as the manufacturer can use the same machining settings. The disadvantage of this is the extra cost of a few extra holes. The original dimensions of the frame had to be changed after getting a 3D-model of the normal force hydraulic cylinder, which did not fit between the vertical bars. The raw material of the bars is 110x110 mm square bar made from S355JR structural steel and top, and bottom plates are made from $110 \mathrm{~mm}$ thick S355J2+N plates. After machining, bars should be $104 \times 104 \mathrm{~mm}$ and plate $104 \mathrm{~mm}$ thick. The final dimensions of the frame are in Figure 6.

The endplates have machined pockets where vertical bars fit. The side surfaces of the pockets, which location is closest to the center of the frame, work as a positioning surface during assembly. Mounting plates for the hydrostatic bearing and the EP are mounted on top of L-blocks. The same blocks mount the torque frames and to give extra support for the connection of vertical bars and top and bottom plates. Dimensions of the L-block are in Figure 7.

Final structural FE-analysis for the frame was made with Ansys, and a displacement result is in Figure 6. Although the distance between vertical bars is greater than in the frame sketch in Figure 5, maximum displacement caused by $250 \mathrm{kN}$ force is only $0.136 \mathrm{~mm}$. The highest von Mises stress of $70 \mathrm{MPa}$ is located in the middle of the bottom plate.

When torque frames, presented in the next section were designed, the lowest natural frequency of the frame was examined with Ansys modal analysis. Natural frequency is $31.5 \mathrm{~Hz}$ with stiffened protection plates. The mode shape of the natural frequency is presented in Figure 8. The masses of the cylinders and other inner components were not taken into account in the simulation, which means that real natural frequency will be lower. 


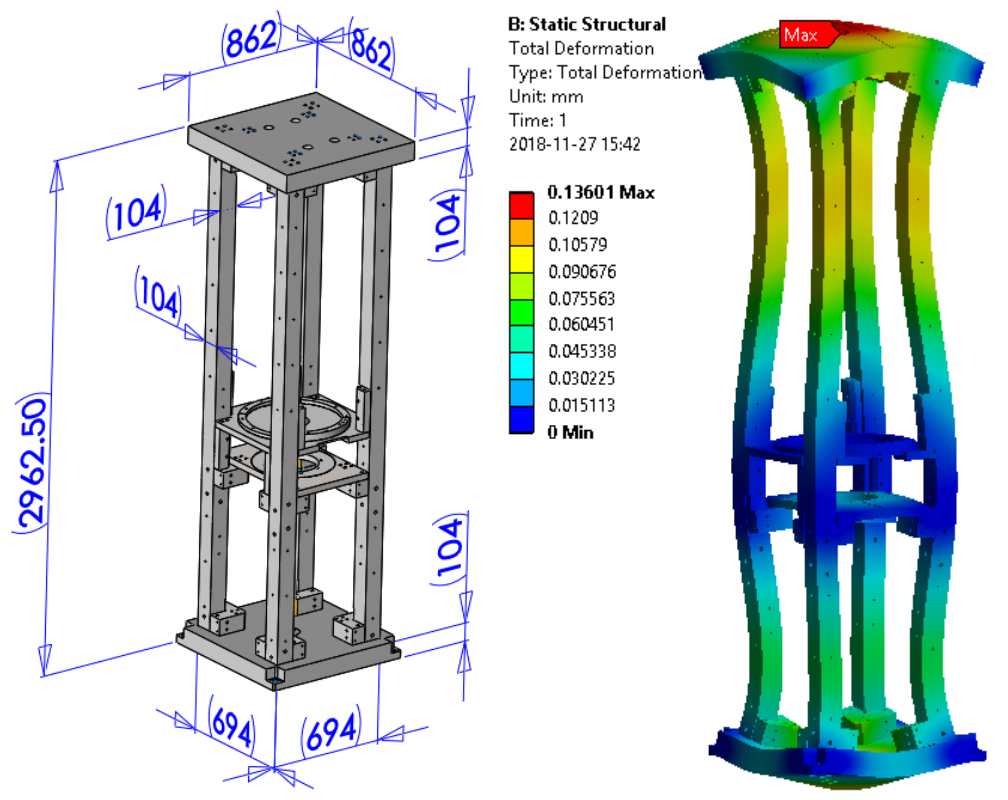

Figure 6. Final dimensions of frame and FE-analysis result made with Ansys

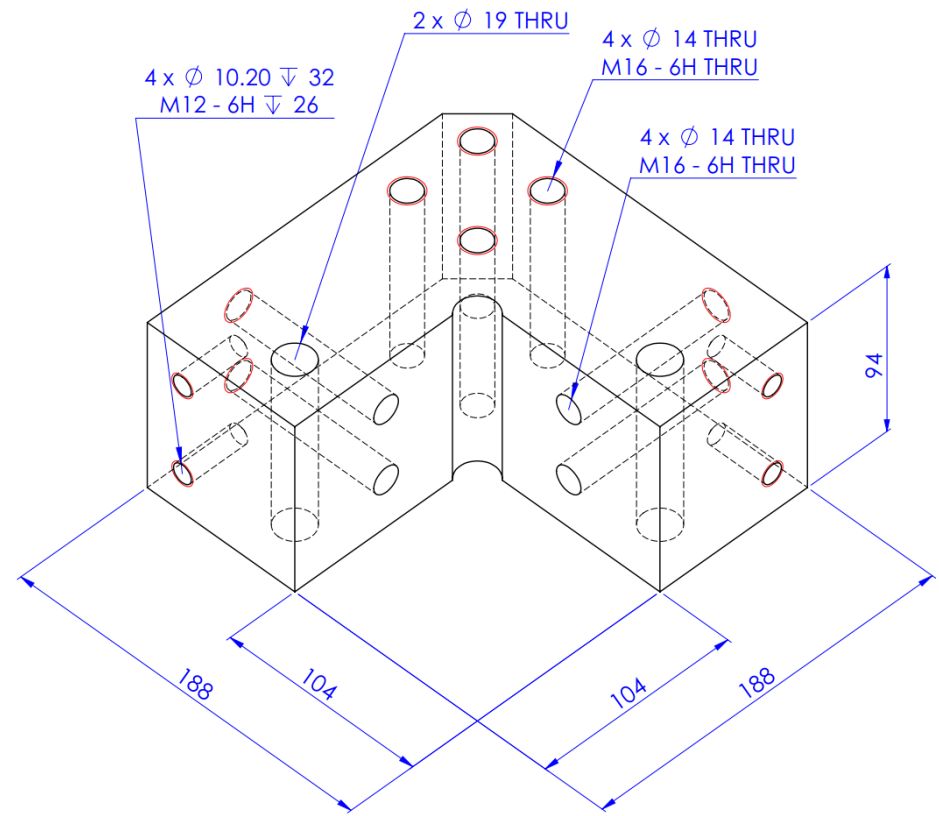

Figure 7. L-block.

\section{Torque frame}

Separate torque frames attach torque cylinders to the mainframe. The torque frames needed to be stiff and lightweight because they are hanging from the mainframe. Welded steel 100x50x3 mm RHS-pipe structure provided rigidity and lightness. Frame design changed significantly, when it was decided that $400 \mathrm{~mm}$ and $800 \mathrm{~mm}$ lever sizes are used instead of $500 \mathrm{~mm}$ lever. Final torque frame structure can be seen in Figure 9.

Each torque frame lays on top of two L-blocks according to Figure 1 and additional support are provided by two top supports, which are bolted straight to the side of the 

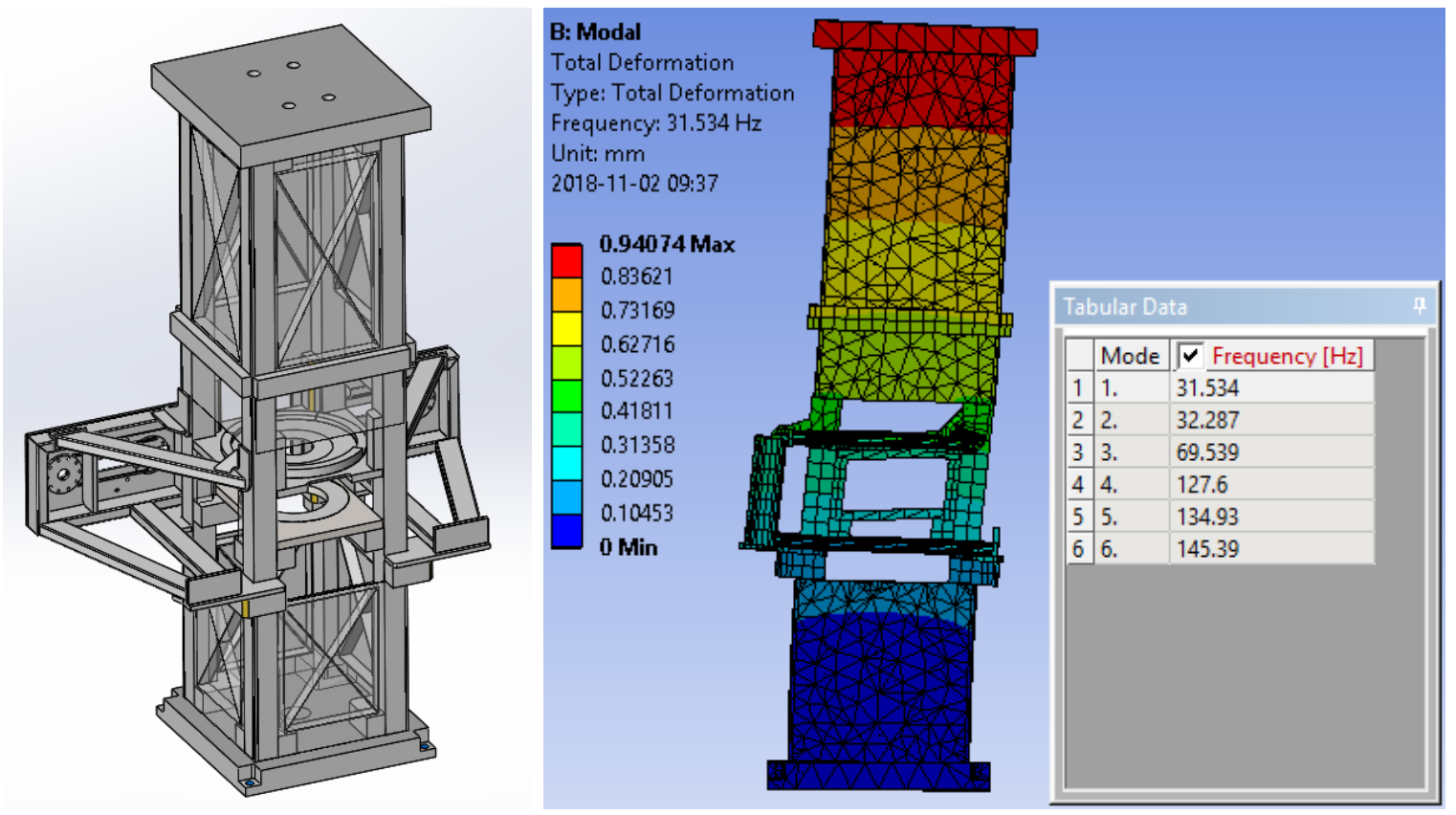

Figure 8. Modal analysis of the simplified frame model

vertical bars of the mainframe. The torque frame consists of two base plates, which have matching holes with L-blocks. Longitudinal RHS-pipe connects them. At the back of the torque frame, there is a large vertical plate, which has laser-cut mounting holes for the torque cylinder and locating studs, which helps to locate vertical plate to the rear base plate when the frame is welded. The vertical plate has three long holes, which enable the sliding of the cylinder from $400 \mathrm{~mm}$ lever position to $800 \mathrm{~mm}$ position and vice versa when eight mounting screws are removed, and four loosened. An extra support plate needs to be moved to another position so that it locates near the cylinder.

A calibration frame, which is also in Figure 9, can be attached either to the vertical back plate or vertical front plate. When it is attached to the front side of the torque frame, also an extra support bar must be attached. Also, three mounting parts are needed, where two parts for attaching a load cell to the torque lever and one part for attaching a wire to the load cell. The opposite end of the wire is attached to a DIN 1480 M20 turnbuckle. Another end of the turnbuckle is attached to the end of the calibration frame. Calibration force (MAX $8 \mathrm{kN})$ can be created by turning the turnbuckle. When a user removes attachment screws of the torque cylinders to the lever, an examination of the needed force to cause rotation to the elastic torque shaft is possible.

\section{Elastic torque shaft}

The basic geometry of an elastic torque shaft did not change much from what it was in the concept development phase. The shaft should be slender in a way it can be twisted with minimal torque, but it should be able to carry $250 \mathrm{kN}$ normal load. The steel shaft withstands higher normal stresses compared with torsional stresses. In this case, torsional stress is constantly changing its direction. Because the swivels of the normal force cylinder have clearance, the direction of the normal force cannot change dynamically. Already the initial FE-simulations showed that von Mises stress caused by torsional moment and normal force is so high that material needs to be high strength steel. After multiple 


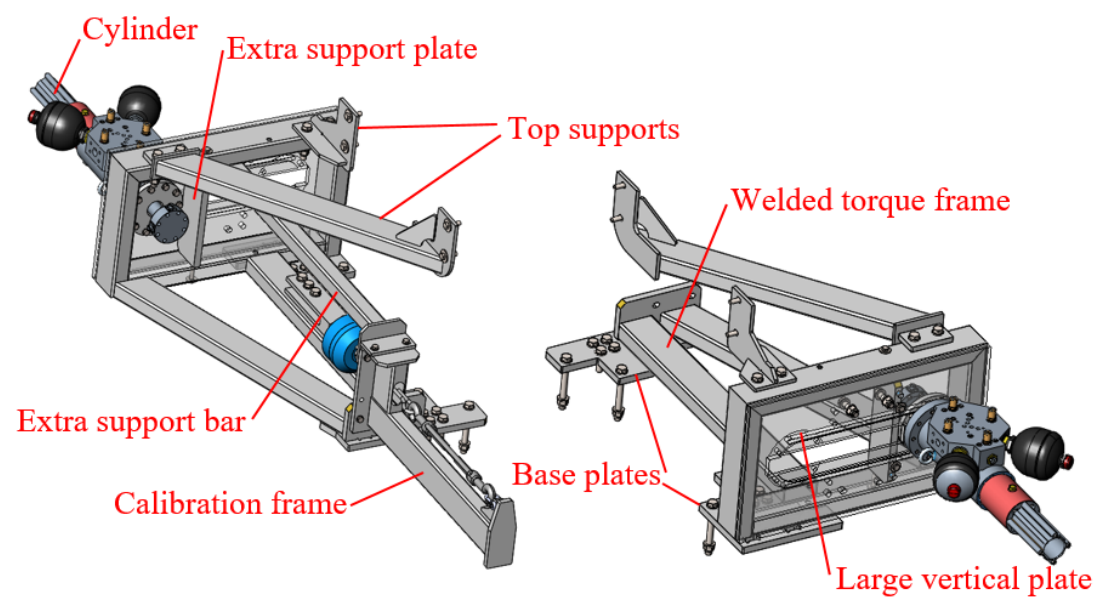

Figure 9. Left side torque frame with and without calibration frame and support bar.

iterations with different size shafts, final dimensions presented in Figure 10 were achieved. Maximum von Mises stress for the shaft is $266 \mathrm{MPa}$ and normal displacement $0.38 \mathrm{~mm}$ when the normal force is $250 \mathrm{kN}$ and torque $1180 \mathrm{Nm}$. The end of the shaft rotates $0.0132 \mathrm{rad}$, which corresponds with $210 \mu \mathrm{m}$ slip amplitude with the $16 \mathrm{~mm}$ middle radius specimen. Eulerâ $\epsilon^{\mathrm{TM}} \mathrm{s}$ critical load was calculated for the $406 \mathrm{~mm}$ long section with the $47 \mathrm{~mm}$ diameter with the condition where only the lower end is fixed. Calculated critical load is $753 \mathrm{kN}$ and safety against buckling with $259 \mathrm{kN}$ normal load is 3.0 .

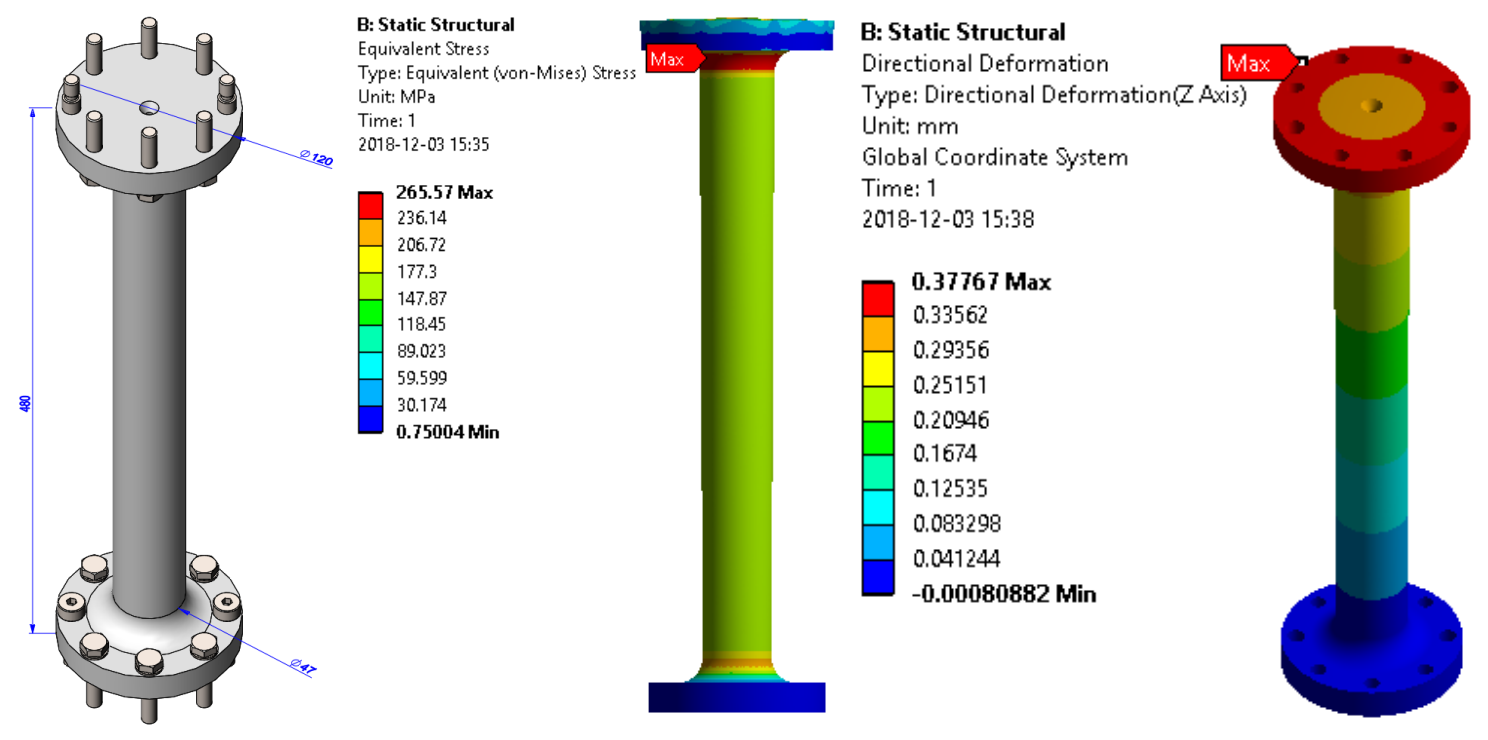

Figure 10. a) Dimensions of elastic torque shaft, b) von Mises stress and c) deformations simulated with Ansys using $1180 \mathrm{Nm}$ torque and $250 \mathrm{kN}$ normal force.

The fatigue durability of the elastic torque shaft is examined in [20] according to the procedure found in reference [21]. First it was calculated that $250 \mathrm{kN}$ normal force causes 144.1 MPa normal stress and $1180 \mathrm{Nm}$ torque causes $57.9 \mathrm{MPa}$ shear stress. Size, surface quality, and notch factors for the shaft were calculated, and then fatigue limit values were interpreted from the Smith diagrams, and values were $500 \mathrm{MPa}$ for normal force load and $370 \mathrm{MPa}$ for torque load. A safety factor against the normal load is 2.5 and against 
torque load 4.3. A combined safety factor is 2.1. For extra safety, also the normal force was considered fully alternating.

The elastic torque shaft alignment on the base plate of the frame with sufficient accuracy, as well as hydrostatic bearing alignment on top of the elastic torque shaft, is essential. The authors considered three different positioning methods. The base plate and the torque shaft could have milled or turned shoulders for positioning, which would provide the best concentricity. Using structural alignment would mean that the user should remove parts by pulling axially. The authors thought that the shaft should be able to be removed by sliding in the radial direction. Positioning elements, according to DIN 6321 standard, could be a suitable positioning method, but they also prevent the radial removal of the shaft. The selected positioning method was two ISO 7379 shoulder screws, which has $12 \mathrm{~mm}$ f9 cylindrical positioning surface and M10 thread. Positioning accuracy between the elastic torque shaft and the shaft of the hydrostatic bearing should be at least $0.1 \mathrm{~mm}$.

\section{Hydrostatic bearing}

The basic idea for the hydrostatic bearing is to provide high radial stiffness as well as minimal external frictional torque to the reciprocating test specimen. See [20] for the hydrostatic bearing initial dimensioning. To ease the manufacturability of the bearing bore, see Figure 11, manufacturing tolerance was lowered from IT5 to IT6, which means $25 \mu \mathrm{m}$ tolerance zone with $180 \mathrm{~mm}$ diameter. The tolerance of the shaft was kept at IT5 $(18 \mu \mathrm{m}$ tolerance zone). The oil was changed from VG32 $(\nu=28.8 \mathrm{cSt})$ to VG46 $(\nu$ $=40.8 \mathrm{cSt}$ ) to increase viscosity. It reduced the required pumping power, almost $30 \%$. Hydrostatic bearing and hydraulic cylinders will have separate oil pumps. Minimum value for the oil film thickness was calculated by summing up the tolerance zones of shaft and bore $\left(h 0_{m} i n=18 \mu \mathrm{m}+25 \mu \mathrm{m}=43 \mu \mathrm{m}\right)$ and maximum value was 1.5 times the minimum value $\left(h 0_{m} a x=1.5 \times 43 \mu \mathrm{m}=64.5 \mu \mathrm{m}\right)$. The bore diameter is thus $180 \mathrm{~mm} \mathrm{H6}$ and shaft diameter $180 \mathrm{~mm}-2 \times 43 \mu \mathrm{m}=179.914 \mathrm{~mm}$ h5.

Table 2. Initial values for dimensioning hydrostatic bearings 1 and 2 .

\begin{tabular}{llll}
\hline Parameter: & Symbol: & Value: & Unit: \\
\hline Number of recesses & $n$ & 4 & $\mathrm{pcs}$. \\
Manufacturing tolerance & $\delta_{g}$ & 18.25 & $\mu \mathrm{m}$ \\
Oil film thickness & $h_{0}$ & $43-64.5$ & $\mu \mathrm{m}$ \\
Max eccentricity & $\varepsilon_{M}$ & 0.5 & \\
Pressure ratio & $\beta$ & $0.4-0.8$ & \\
Oil density & $\rho$ & 859 & $\mathrm{~kg} / \mathrm{m}^{3}$ \\
Kinematic viscosity & $\nu$ & 40.8 & $\mathrm{~mm}^{2} / \mathrm{s}, \mathrm{cST}$ \\
Dynamic viscosity & $\eta_{0}$ & 0.035 & $\mathrm{Ns} / \mathrm{m}^{2}, \mathrm{P}$ \\
Specific heat capacity & $c_{0}$ & 1922 & $\mathrm{~J} / \mathrm{kgK}$ \\
Bulk temperature & $T_{b}$ & 48.5 & ${ }^{\circ} \mathrm{C}$ \\
\hline
\end{tabular}

Initial values for the Mathcad calculation are in Table 2 for both bearings 1 and 2 . The differing values, like loads, dimensions, pressure ratios, and oil film thicknesses, are in Table 3. The orifice diameter used was $0.55 \mathrm{~mm}$ and results for both $64.5 \mu \mathrm{m}$ and $43 \mu \mathrm{m}$ 
film thicknesses were calculated. Pressure ratios $\beta$ are almost in the range of 0.4 to 0.7 what Rowe recommended in [24], so $0.55 \mathrm{~mm}$ diameter is good starting value for the orifice. The user can change orifices after testing the bearing to optimize the performance. As can be seen from Table 4, if actual film thickness is $64.5 \mu \mathrm{m}$, using $1.00 \mathrm{~mm}$ orifice instead of 0.55 would lead to $24 \%$ lower radial displacement, but this means that required oil flow almost doubles.

Table 3. Initial values and calculated results from Mathcad for lowest and highest possible radial stiffness with $0.55 \mathrm{~mm}$ orifice restrictor

\begin{tabular}{|c|c|c|c|c|}
\hline Parameter/Result & Symbol & $\begin{array}{l}\text { Bearing } 1 \\
\text { Value }\end{array}$ & $\begin{array}{l}\text { Bearing } 2 \\
\text { Value }\end{array}$ & Unit \\
\hline \multicolumn{5}{|l|}{ (Parameters) } \\
\hline Load & $W_{M}$ & 107.95 & 82.45 & $\mathrm{kN}$ \\
\hline Diameter & $D_{B}$ & 180 & 180 & $\mathrm{~mm}$ \\
\hline Length & $L_{B}$ & 240 & 200 & $\mathrm{~mm}$ \\
\hline Intern recess land width & $b_{B}$ & 47.1 & 47.1 & $\mathrm{~mm}$ \\
\hline Land width & $a_{B}$ & 72 & 68 & $\mathrm{~mm}$ \\
\hline Pressure ratio & $\beta$ & 0.400 & 0.385 & \\
\hline $\begin{array}{l}\text { Oil film thickness } \\
\text { (Results) }\end{array}$ & $h_{0}$ & 64.5 & 64.5 & $\mu \mathrm{m}$ \\
\hline Radial displacement & $e_{d_{-} o r}$ & 17.7 & 15.1 & $\mu \mathrm{m}$ \\
\hline Oil flow & $q_{B}$ & 6.8 & 6.9 & $\mathrm{l} / \mathrm{min}$ \\
\hline Pumping power & $H_{P}$ & 3.2 & 3.2 & $\mathrm{~kW}$ \\
\hline $\begin{array}{l}\text { Orifice size } \\
\text { (Parameters) }\end{array}$ & $d_{o r}$ & 0.55 & 0.55 & $\mathrm{~mm}$ \\
\hline Pressure ratio & $\beta$ & 0.780 & 0.765 & \\
\hline $\begin{array}{l}\text { Oil film thickness } \\
\text { (Results) }\end{array}$ & $h_{0}$ & 43 & 43 & $\mu \mathrm{m}$ \\
\hline Radial displacement & $e_{d_{-} o r}$ & 8.8 & 7.6 & $\mu \mathrm{m}$ \\
\hline Oil flow & $q_{B}$ & 3.9 & 4.1 & $1 / \min$ \\
\hline Pumping power & $H_{P}$ & 1.9 & 1.9 & $\mathrm{~kW}$ \\
\hline Orifice size & $d_{o r}$ & 0.55 & 0.55 & $\mathrm{~mm}$ \\
\hline
\end{tabular}

See Figure 11 for a list of parts of the hydrostatic bearing. Bearing mounts from the upper seal housing to frame, and four extra supports attach between the lower seal housing and the vertical bars of the frame. Oil pressure sensors are connected to every recess so that that actual recess pressures can be measured. If the greatest film thickness realizes and best radial stiffness is required, an oil pump, which provides at least $27 \mathrm{l} / \mathrm{min}$ oil flow with 280 bar pressure, is needed. Pressure sensors data correlates with the radial forces, which originate from the fretting contact. It could give new information about the distribution of adhesion forces.

Authors know that the manufacturing of parts for the hydrostatic bearing could be challenging; therefore, we made detailed manufacturing drawings as soon as possible to request quotations. Research engineers from the technical and maintenance services of Tampere University helped to set the tolerance limits. 
Table 4. Results with high film thickness and $1.0 \mathrm{~mm}$ orifice diameter.

\begin{tabular}{lllll}
\hline & & $\begin{array}{l}\text { Bearing 1 } \\
\text { Value }\end{array}$ & $\begin{array}{l}\text { Bearing 2 } \\
\text { Value }\end{array}$ & Unit \\
\hline $\begin{array}{l}\text { Parameter/Result } \\
\text { Pressure ratio }\end{array}$ & $\beta$ & 0.790 & 0.759 & \\
$\begin{array}{l}\text { Oil film thickness } \\
\text { (Results) }\end{array}$ & $h_{0}$ & 64.5 & 64.5 & $\mu \mathrm{m}$ \\
Radial displacement & $e_{d \_o r}$ & 13.4 & 11.3 & $\mu \mathrm{m}$ \\
Oil flow & $q_{B}$ & 13.3 & 13.5 & $\mathrm{l} / \mathrm{min}$ \\
Pumping power & $H_{P}$ & 6.2 & 6.3 & $\mathrm{~kW}$ \\
Orifice size & $d_{o r}$ & 1.00 & 1.00 & $\mathrm{~mm}$ \\
\hline
\end{tabular}

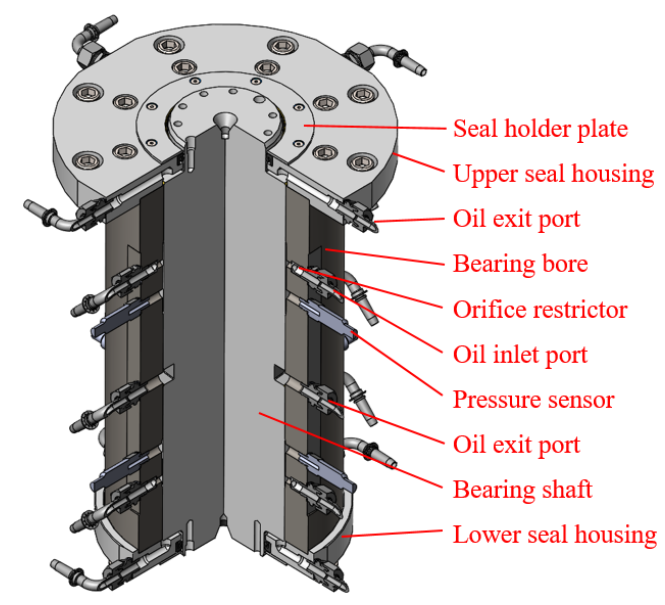

Figure 11. Parts of hydrostatic bearing

\section{Torque lever}

A torque lever, which is in Figure 12, requires stiffness mainly in the push and pull direction of the torque cylinders, so structural steel plate is a sensible choice for raw material. The upper and lower surfaces of the plate act as a base for positioning, so the surfaces need to be machined. The lever plate has three holes in $400 \mathrm{~mm}$ and $800 \mathrm{~mm}$ lever length, where rod clamps can be bolted. At $600 \mathrm{~mm}$, distance locates three holes for torque calibration that was mentioned in the previous torque frame section. The rod clamps have an M20 thread where elastic rods are attached. A force transducer adapter is attached to the other end of the rod with the same size connection. Nuts secure both ends of the rods. The elastic rod has $120 \mathrm{~mm}$ long thin section with a $13 \mathrm{~mm}$ diameter in the middle, which transmits the normal force from the torque cylinder to the torque lever, but it transmits only a tiny bending moment from the torque lever to the cylinder piston. A safety factor against buckling is 2.2 , when the free rod end, $13 \mathrm{~mm}$ diameter and $209 \mathrm{~mm}$ free length was used. FE-analysis performed with Ansys resulted in a 2.9 buckling safety factor and 66.1 MPa von Mises stress. Total deformation was $0.046 \mathrm{~mm}$.

The torque lever is positioned on top of the shaft of the hydrostatic bearing the same way as the elastic torque shaft is positioned to the frame, using shoulder screws. There are also two positioning holes for shoulder screws on top of the lever for positioning a 
lower specimen holder. Because friction torque is measured with force transducers, which locates at the end of the piston of the torque cylinder, the compliance of the torque lever must be taken into account in the same way as the compliance of the specimens when the needed stroke of the torque cylinders is calculated.

FE-analysis was performed with Solidworks to find out what the compliance is with $800 \mathrm{~mm}$ lever position and $400 \mathrm{~mm}$ lever position. The lever assembly and von Mises stress results are in Figure 13. The torque values used in the analysis were calculated in Table 1. The following equation shows the compliance for $800 \mathrm{~mm}$ lever position

$$
k_{800}=\frac{\Delta s}{r \cdot T}=\frac{0.0277784 \mathrm{~mm}}{140 \mathrm{~mm} \cdot 9204 \mathrm{Nm}}=2.1558 \times 10^{-8} \mathrm{rad} / \mathrm{Nm}
$$

where $\Delta s$ is rotation displacement, $\mathrm{r}$ is examination distance from central axis and $\mathrm{T}$ torque. Compliance for $400 \mathrm{~mm}$ position is

$$
k_{400}=\frac{\Delta s}{r \cdot T}=\frac{0.021409 \mathrm{~mm}}{140 \mathrm{~mm} \cdot 5791 \mathrm{Nm}}=2.6407 \times 10^{-8} \mathrm{rad} / \mathrm{Nm}
$$

For comparison, the compliance of D150d100t25 specimen was $2.4815 \times 10^{-8} \mathrm{rad} / \mathrm{Nm}$, which is only $15 \%$ higher than the compliance of the lever in $800 \mathrm{~mm}$ position. The von Mises stress of the elastic rod is $25 \%$ higher with $400 \mathrm{~mm}$ lever position although the torque is $37 \%$ smaller than with $800 \mathrm{~mm}$ position.

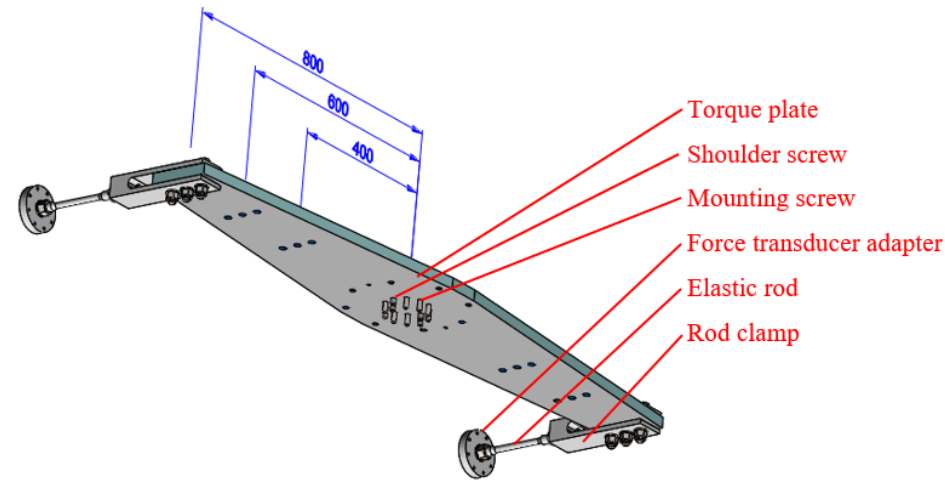

Figure 12. Torque lever and other parts

\section{Specimen holders}

As can be deduced from [20], the structure of the specimen holders should be as low as possible, so that the radial forces would not cause so much bending moment. However, visibility to the side of the contact should be available so that microscope photography can be utilized. The basic structures of the specimen holder took shape already in the concept phase.

Positioning holes for shoulder screws were added to the lower specimen holder in the detail design phase. Distance sensors were selected, and holders were designed to support them. A concentricity sleeve was designed to align the specimen holders. The specimen holders and other parts are in Figure 14 in their final form. The normal distance sensor locates in the middle of the upper specimen holder, as shown in Figure 2. Rotation sensors locate on the edge of the upper specimen holder, so that distance from the central axis 

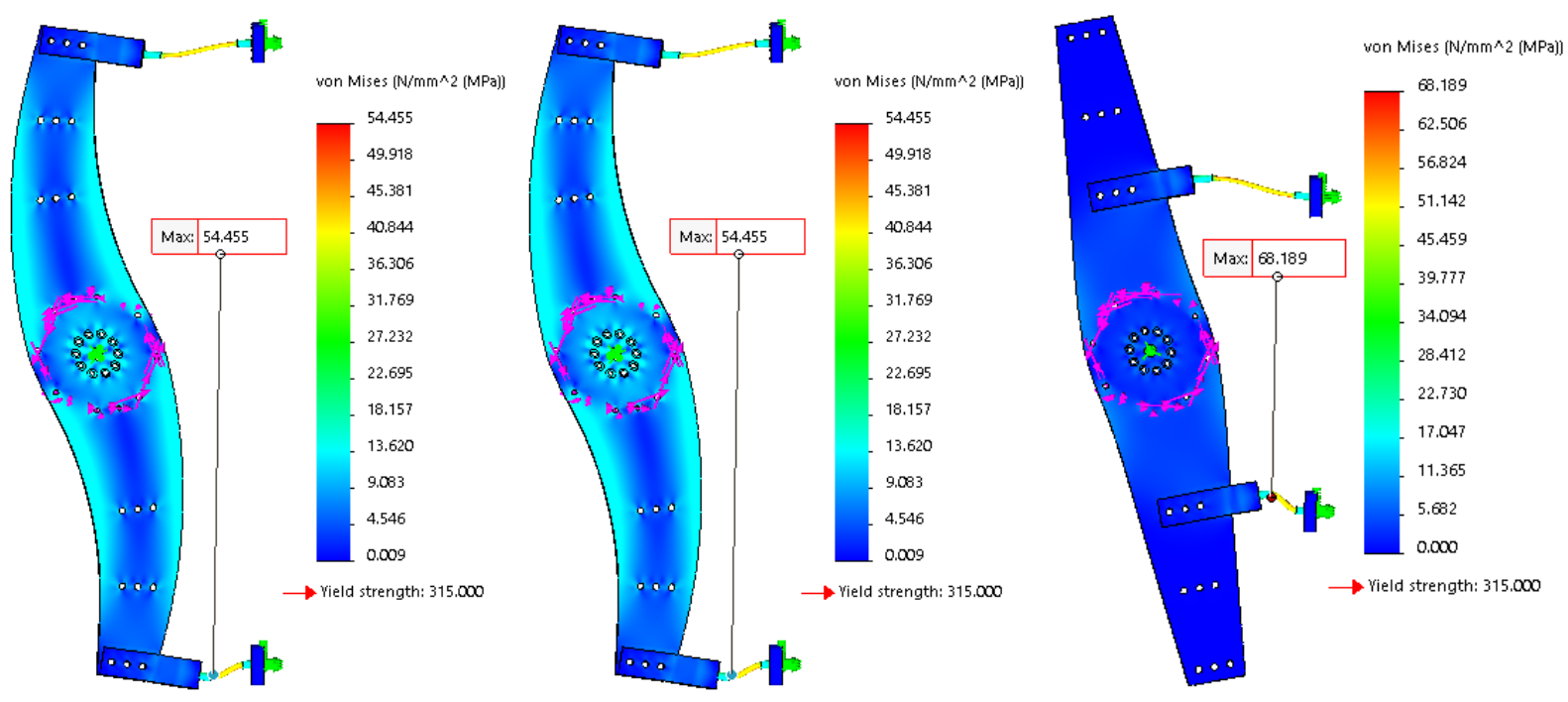

Figure 13. FE-analysis results for $800 \mathrm{~mm}$ lever position with $9204 \mathrm{Nm}$ torque and $400 \mathrm{~mm}$ position with $5791 \mathrm{Nm}$ torque (deformation scale $=2000$ ).

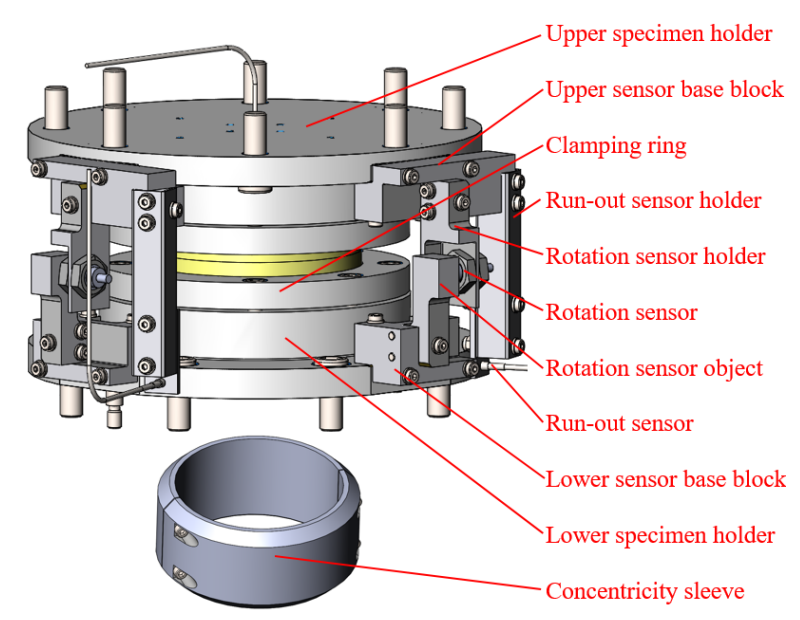

Figure 14. Specimen holders and other parts.

to the sensor is the same with both small and large specimens, which have different size tapers and specimen holders. A measurement object is attached to the lower specimen holder. A run-out sensor is attached to the upper specimen holder, and it measures distance deviations from an outer cylindrical surface of the lower specimen holder. Four M6 threaded holes were added to the bottom of the specimen holders so that the screws could be used to push the jammed specimen off. The tapered connection dimensioning is in its section on page 311.

A specimen change procedure begins with the removal of the screws of the lower specimen holder ( $8 \times$ M16, $2 \times$ shoulder screw). The loose lower specimen holder can be pulled forward and attached to the auxiliary specimen holding rack shown in Figure 15. A user can remove the clamping ring by loosening eight M10 screws. Then the specimen can be pulled out, or if it is stuck, four M6 screws can be used to push it out. After removing the M6 screws, a new specimen can be set in place and clamping ring attached by fastening the screws to the desired tightening torque. 


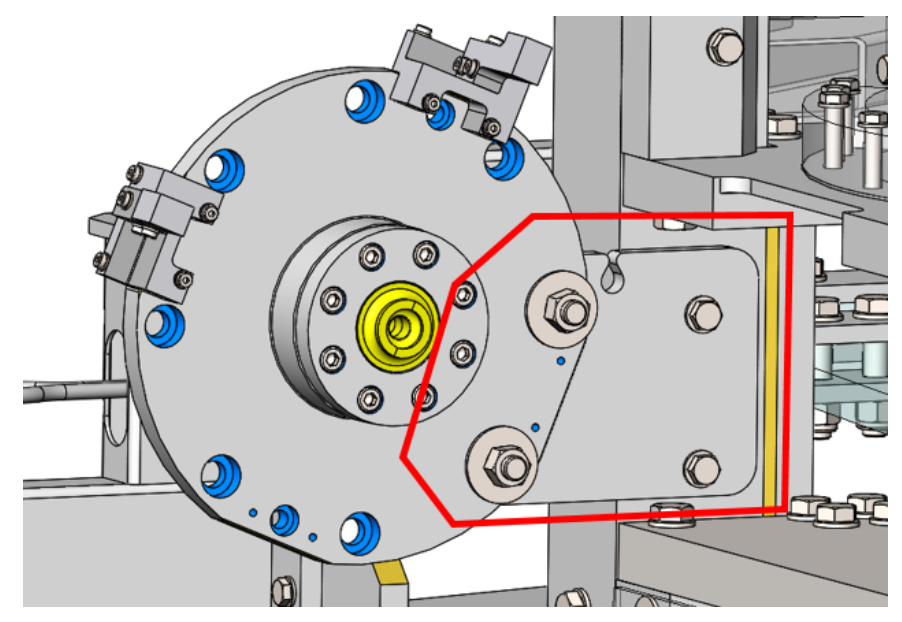

Figure 15. Lower specimen holder attached to the auxiliary specimen holding rack

If the lower specimen removal is easy, it is likely that the upper specimen is also easily removed just by removing eight M10 screws of the clamping ring and pulling it out. If the upper specimen is stuck, the user needs to remove the upper specimen holder by removing eight M16 screws. Also, the holders of the run-out sensors must be removed to allow the specimen holder to be lowered. The cables of the rotation sensors and the normal distance sensor are so long that the specimen holder can be attached to the removal rack without removing them. The tested specimen is removed and a new specimen attached using the same tightening torque as with the lower specimen. Holes of the upper specimen holder align with the EP, and the holder is supported up so that M16 screws reach their holes and can be screwed so that the holder can still be rotated. The run-out sensor holder is attached to the upper specimen holder, and then the lower holder can be attached. The concentricity sleeve tightens around the holders, and the screws of the upper specimen holder are tightened.

\section{Axial displacement plate}

Axial displacement plate (EP) was dimensioned in [20]. Plate's role is to provide high radial, but low normal stiffness to the fixed test specimen. Holes for fixing the EP to the frame and for fixing the upper specimen holder and contact pressure adjustment assembly to the EP appear in the detail design phase. As can be seen from Figure 16, there are four clamping plates, which fix the EP to the frame with 16 x M16 screws. The front plate is thicker and has more screws to increase stiffness, which is lower in the front because the plate of the frame has a milled groove for the microscope. Also, $180 \mathrm{~mm}$ diameter hole was needed in the middle of the EP.

Two Ansys FE-analysis dimensions the EP. The element size of the first mesh was $3 \mathrm{~mm}$ and the second $0.5 \mathrm{~mm}$. $2500 \mathrm{~N}$ normal force was directed to a top face of a thick section in the middle, according to Figure 17. It caused $1.1 \mathrm{~mm}$ normal displacement. $9204 \mathrm{Nm}$ torque was applied to the same surface and a bottom surface in the middle. Maximum von Mises stress was $153 \mathrm{MPa}$ in the first test and $189.8 \mathrm{MPa}$ in the second test, and maximum stress location is on the singularity edge of the plate and thicker middle section. Because stress is high, the material choice was ultra strong S960QL (1.8933) steel. 


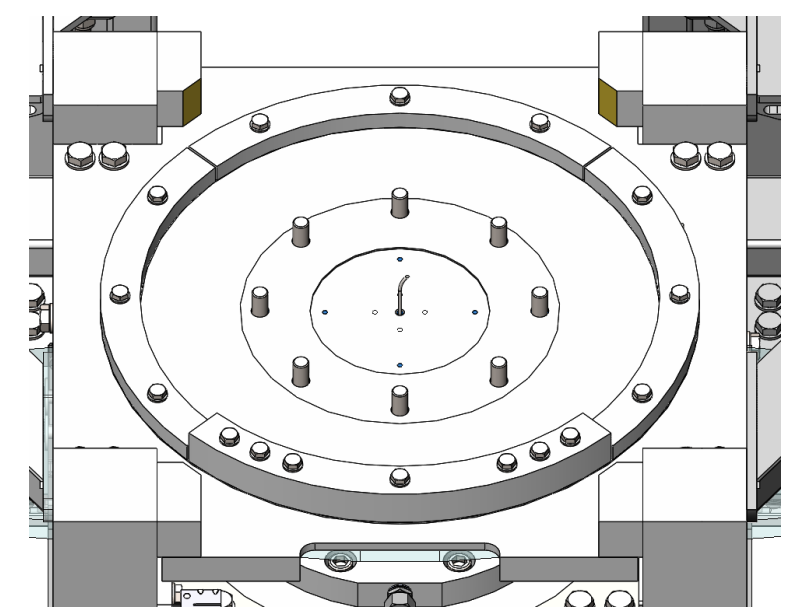

Figure 16. Axial displacement plate attached to the frame

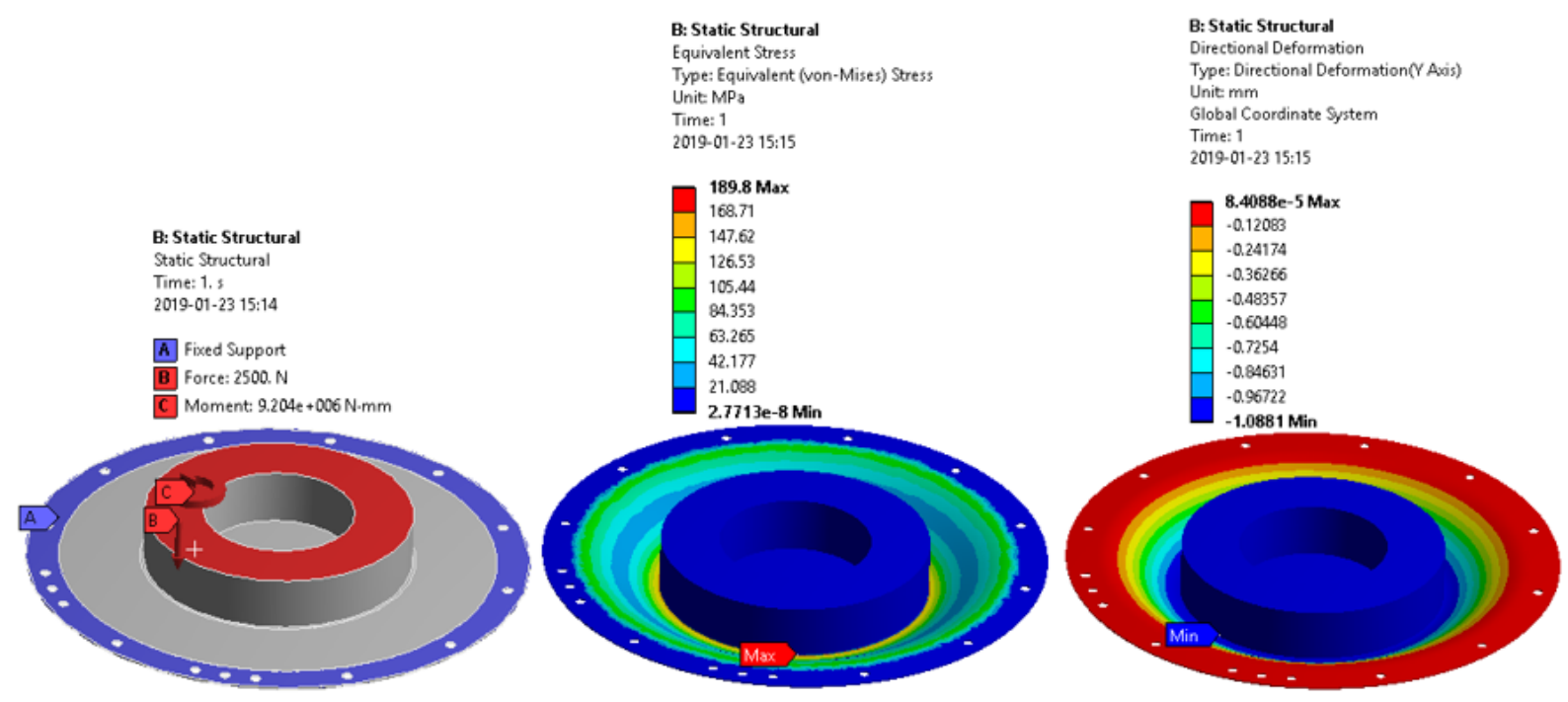

Figure 17. Results of Ansys FE-analysis for the elastic axial displacement plate (EP).

\section{Contact pressure adjustment}

There are four specimen parallelism adjustment screws in the current fretting apparatus. They are used to equalize contact pressure. In the ideal case, all screws have the same amount of tensile stress created by tightening nuts. Contact pressure examination happens with a pressure-sensitive film, and if it is lower on one side, pressure increases by tightening the nut on the corresponding side. The new contact pressure adjustment system uses the same proven principle, which is in Figure 18.

In the current apparatus, contact pressure changed substantially with very little rotation of the adjustment nut. Thus fine adjustment threads were used in the new rig. KMT 4 M20x1.0 precision lock nuts manufactured by SKF were selected because there were no finer threaded nuts available in that size. The nut can be locked in its position with three M6 set screws. The elastic pulling rod has $10 \mathrm{~mm}$ diameter and $130 \mathrm{~mm}$ long thinned section in the middle, which allows an adjustment box to move in the normal direction. On the other end, there is a standard pitch M20 thread. Rod attaches with two nuts to 


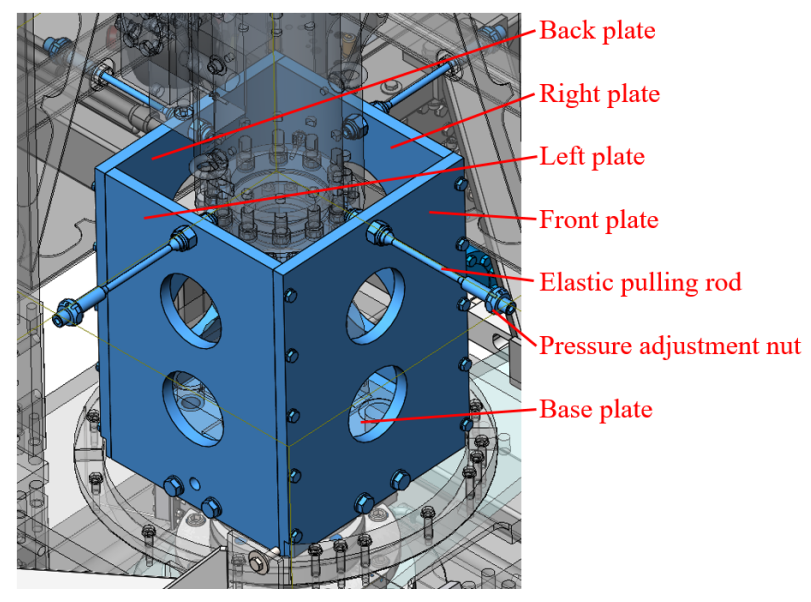

Figure 18. Contact pressure adjustment system

the adjustment box, which consists of a base plate and four vertical plates, each attached to the base plate with two M16 screws. Also, the vertical plates are bind together with 20 x M10 screws. The base plate has threaded holes for mounting the upper specimen holder and a swivel of the hydraulic cylinder. Upper protective plates of the frame have holes from which the pulling rod goes through. The rod also goes through a 60x60x5 RHS pipe, which works as a support against the pulling force.

\section{Conclusions}

The designing of the new fretting test rig was carried out by adapting the generic development process model. A list of requirements and desires for the new fretting test rig was compiled together with an industrial partner. There were requirements for the contact type, the measurable and the controllable parameters, and for the other functions like microscope photography. The main challenge in the development of the new fretting test rig was to create as stiff bearing as possible both in the normal and radial direction to minimize the run-out between specimens with high normal loads.

The fully hydrostatic bearing concept and the combination of the hydrostatic journal bearing and elastic torque shaft were chosen for further examination because the hydrostatic bearings offer unrivaled stiffness and low friction compared with the other supporting solutions. The normal force of $250 \mathrm{kN}$ was found to be sufficient to create $400 \mathrm{MPa}$ contact pressure for large enough specimens. The elastic torque shaft was chosen to support the normal force because it is much simpler than the hydrostatic opposed pad bearing.

After the decision of the locations of the main components, the frame designing started. The main frame consisting of four vertical bars and bottom and top plates, was designed first. Then, the torque frames were designed to support the torque cylinders. The frames, as the main components, find their final design. For example, the selected normal force cylinder with the pressure accumulator and two swivels was so large that the vertical bars had to be moved farther apart from each other and extended. Also, the bottom supports appeared for the hydrostatic bearing. FE-analysis was used to find out the natural frequency of the whole frame and to find out how much displacement $250 \mathrm{kN}$ normal force causes.

Many solutions, which were found to be working in the current fretting test apparatus, 
were also used in the new test rig, like the elastic rods of the torque lever, the tapered connections of the specimens, axial displacement plate, and contact pressure adjustment system. However, all parts need to withstand higher forces, and this is achieved using FE-simulation conducted with both Solidworks and Ansys. Also, the authors made a calibration system design. The calibration force created with the turnbuckle and measured with the verified force transduces of Tampere University. The authors performed the selection of the distance sensors and their mounting structures. To increase operational safety, and the rigidity of the frame, the stiffened protective plates were added on the outer surfaces of the frame. The specimen removal rack was added to make removing and attaching of the specimens easier. The adjustable anti-vibration machine feet appear between the frame and the laboratory floor. They can be used to mount the base plate horizontally. The manufacturing drawings were made for the parts of the hydrostatic bearings so that quotations could be requested.

The hydraulic cylinders could be selected directly from the supplierâ $€^{\mathrm{TM}} \mathrm{s}$ catalog based on the needed force. The force transducers, pressure accumulators, servo valves, and safety valves were chosen in cooperation with the supplier. The function of cylinders was simulated to find out the needed oil flow, which was then be used to select the hydraulic pump. Also, the needed oil flow calculation for the hydrostatic bearing and pump chosen for it was done. The higher viscosity oil means smaller oil flow requirement.

The designed fretting test rig fulfills almost all of the requirements from the project beginning. It can perform fretting tests with $245 \mathrm{kN}$ maximum normal force and $23200 \mathrm{Nm}$ maximum torque, which allows $24 \mathrm{MPa}$ contact pressure tests with $150 \mathrm{~mm}$ outer diameter specimens. $400 \mathrm{MPa}$ tests can be made with $38 \mathrm{~mm}$ outer diameter specimens. Testing of even smaller specimens is possible, but there should be $14 \mathrm{~mm}$ diameter hole in the middle of the specimen. The control of the normal force and normal movement are independent of the torque control and rotation control. The cycle frequency can be minimal if needed. The normal force cannot change from compression to tension dynamically or the swivels, which have clearance, will break down. The control system of the cylinders should have limits so that the maximum stroke length of the normal force cylinder and the maximum stroke amplitude of the torque cylinder are not exceeded, or elastic torque shaft and elastic axial displacement plate may break down due to fatigue. This work includes only the compliance of the specimens. Before the tests, also the compliances of the specimen holders should be analyzed so that the slip can be identified more accurately from measured rotation. In addition, the microscope can be used to record events at the contact edge.

\section{Acknowledgments}

Authors would like to acknowledge the financial support of Business Finland (former Tekes) in the form of a research projects WIMMA Dnro 1566/31/2015, MaNuMiES Dnro 3361/31/2015, ISA Wärtsilä Dnro 7734/31/2018 and ISA TAU Dnro 7204/31/2018.

\section{References}

[1] Tero Frondelius, Hannu Tienhaara, and Mauri Haataja. History of structural analysis \& dynamics of Wärtsilä medium speed engines. Rakenteiden Mekaniikka, 51(2):1-31, 2018. open access. URL: https://doi.org/10.23998/rm.69735. 
[2] Antti Mäntylä, Jussi Göös, Anton Leppänen, and Tero Frondelius. Large bore engine connecting rod fretting analysis. Rakenteiden Mekaniikka, 50(3):239-243, 2017. open access. URL: https://doi.org/10.23998/rm.64914.

[3] Bharat Bhushan. Introduction to tribology. John Wiley \& Sons, 2013.

[4] Robert Barry Waterhouse. Fretting fatigue. Elsevier Science \& Technology, 1981.

[5] A Pasanen, S Järvisalo, A Lehtovaara, and R Rabb. Development of a test device for the evaluation of fretting in point contact. Lubrication Science, 21(2):41-52, 2009.

[6] Arto Lehtovaara and Roger Rabb. A numerical model for the evaluation of fretting fatigue crack initiation in rough point contact. Wear, 264(9):750-756, 2008.

[7] Jouko Hintikka, Arto Lehtovaara, and Christian Lönnqvist. Effect of start-up schemes and amplitude of tangential motion on friction behavior in fretting point contact. Tribology International, 44(11):1535-1543, 2011.

[8] Jouko Hintikka, Arto Lehtovaara, and Antti Mäntylä. Fretting fatigue and friction of quenched and tempered steel in dry contact with aluminum bronze. Wear, 308(1):155-165, 2013.

[9] Janne Juoksukangas, Arto Lehtovaara, and Antti Mäntylä. The effect of contact edge geometry on fretting fatigue behavior in complete contacts. Wear, 308(1):206-212, 2013.

[10] Jouko Hintikka, Arto Lehtovaara, and Antti Mäntylä. Non-coulomb friction in gross sliding fretting conditions with aluminium bronze against quenched and tempered steel. Tribology International, 79:151-161, 2014.

[11] Jouko Hintikka, Arto Lehtovaara, Tero Frondelius, and Antti Mäntylä. Tangential traction instability in fretting contact below fully developed friction load. Rakenteiden Mekaniikka, 50(3):175-178, 2017. open access. URL: https://doi.org/10.23998/ rm. 65105 .

[12] Jouko Hintikka, Jouko Juoksukangas, Arto Lehtovaara, Tero Frondelius, and Antti Mäntylä. Non-idealities in fretting contacts. Rakenteiden Mekaniikka, 50(3):171-174, 2017. open access. URL: https://doi.org/10.23998/rm.64886.

[13] Jouko Hintikka, Antti Mäntylä, Joona Vaara, Tero Frondelius, and Arto Lehtovaara. Stable and unstable friction in fretting contacts. Tribology International, 131:73 - 82, 2019. open access. URL: https://doi.org/10.1016/j.triboint.2018.10.014.

[14] Janne Juoksukangas, Arto Lehtovaara, and Antti Mäntylä. Experimental and numerical investigation of fretting fatigue behavior in bolted joints. Tribology International, 103:440-448, 2016.

[15] Antti Mäntylä, Janne Juoksukangas, Jouko Hintikka, and Tero Frondelius. FEMbased wear simulation for fretting contacts. Rakenteiden Mekaniikka.

[16] Janne Juoksukangas, Jouko Hintikka, Arto Lehtovaara, Antti Mäntylä, Joona Vaara, and Tero Frondelius. Avoiding the high friction peak in fretting contact. Rakenteiden Mekaniikka, 53(1):12-19, 2020. open access. doi:10.23998/rm.76266. 
[17] Jouko Hintikka, Arto Lehtovaara, and Antti Mäntylä. Normal displacements in non-coulomb friction conditions during fretting. Tribology International, 94:633-639, 2016.

[18] Janne Juoksukangas, Verner Nurmi, Jouko Hintikka, Minnamari Vippola, Arto Lehtovaara, Antti Mäntylä, Joona Vaara, and Tero Frondelius. Characterization of cracks formed in large flat-on-flat fretting contact. International Journal of Fatigue, 124:361 - 370, 2019. open access. URL: https://doi.org/10.1016/j.ijfatigue. 2019.03 .004$.

[19] Verner Nurmi, Jouko Hintikka, Janne Juoksukangas, Mari Honkanen, Minnamari Vippola, Arto Lehtovaara, Antti Mäntylä, Joona Vaara, and Tero Frondelius. The formation and characterization of fretting-induced degradation layers using quenched and tempered steel. Tribology International, 131:258 - 267, 2019. open access. URL: https://doi.org/10.1016/j.triboint.2018.09.012.

[20] Jaakko Meuronen. Development of fretting test rig with dynamic normal force, 2019. Tampere University. Master thesis.

[21] Mauri Airila, Kalevi Ekman, Pekka Hautala, Heikki Martikka, Juha Miettinen, Jari Rinkinen, and Pekka Salonen. Koneenosien suunnittelu. Sanoma Pro Oy, 2010.

[22] Yoshimi Ito and Takashi Matsumura. Theory and practice in machining systems. Springer, 2017.

[23] Jouko Hintikka. Fretting Induced Friction, Wear and Fatigue in Quenched and Tempered Steel. Tampere University of Technology. Publication. Tampere University of Technology, 62016.

[24] W Brian Rowe. Hydrostatic, aerostatic and hybrid bearing design. Elsevier, 2012.

Jaakko Meuronen, Janne Juoksukangas, Arto Lehtovaara

Tribology and Machine Elements, Faculty of Engineering and Natural Sciences

Tampere University

P.O. Box 589, FI-33014 Tampere University, Tampere, Finland

firstname.lastname@tuni.fi

Antti Mäntylä, Joona Vaara, Jouko Hintikka, Tero Frondelius

R\&D and Engineering, Wärtsilä

P.O.Box 244, 65101 Vaasa, Finland

firstname.lastname@wartsila.com

Tero Frondelius

University of Oulu

Erkki Koiso-Kanttilan katu 1

90014 Oulun yliopisto

firstname.lastname@oulu.fi 